\title{
Anthocyanins accumulation and genes-related expression in berries of cv. Tannat (Vitis vinifera L.)
}

\author{
O. Borsani1*, G. Gonzalez-Neves ${ }^{2,3}$, M. Ferrer² and J. Monza ${ }^{1}$ \\ ${ }^{1}$ Laboratorios de Bioquímica and ${ }^{2}$ Viticultura - Enología, Facultad de Agronomía, Avda. Garzón 780 CP 12900. Montevideo, \\ Uruguay, ${ }^{3}$ Instituto Nacional de Vitivinicultura, Dr. Pouey 463. Las Piedras, Uruguay. *E-mail: omarborsani@gmail.com
}

\begin{abstract}
Anthocyanins accumulation and gene expression in berries of Vitis vinifera L. cv. Tannat trained in Lyre system was investigated. Expression of genes involved in anthocyanins biosynthetic pathway as chalcone synthase (CHS), flavonoid 3-hydroxylase (F3H), dihydroflavonol 4- reductase (DFR), and UDP-glucose flavonoid-3-O-glucosyl transferase (UFGT) was examined. On the other hand, the influence of plant architecture, Lyre and vertical shoot positioned (VSP) trellis systems, on anthocyanins accumulation and gene expression was also analyzed. Final contents of total anthocyanins were not affected by trellis systems but varied in two years with different water deficit imposition period. However, the individual profile of the genes and anthocyanidins modified according to the moment of water deficit imposition (veraison or harvest) and by the trellis systems (Lyre or VSP). Analysis of gene expression in Lyre along the berry development period showed that low leaf water potentials after veraison cause an earlier and greater induction compared with expression in a year with low leaf water potential at harvest. At harvest, the hydric deficit induced an increase in the expression of CHS, F3H and DFR genes and a higher total anthocyanins content. The study revealed that plant architecture affect the expression of anthocyanins related gene in berries possibly by modifying the canopy microclimate.
\end{abstract}

Key words: Anthocyanins, anthocyanidins, berries, hydric deficit, Lyre, plant architecture, raisin, transcripts profile, Tannat, veraison, Vitis vinifera L.

\section{Introduction}

Polyphenols are the main components involved in the colouration of grapes and provide the gustative characteristics. Given the inquisitiveness of humans and the importance of wine colour, flavour, and astringency, the management of phenolic compounds is becoming important (Conde et al., 2007). Phenolic compounds of the grape are divided in flavonoids and non- flavonoids groups. Flavonoids include the anthocyanins that are responsible for the characteristic red, blue, and purple colour of plant tissues. Anthocyanins play an important role in plant reproduction and also in protection from different stresses, including photooxidative stress (Winkel-Shirley, 2002).

In grapes, the berry skin accumulates anthocyanins and the relative abundance is determined by the cultivars and also strongly influenced by the environmental conditions under which the vines are cultivated (Keller et al., 2004; 2005). Drought, temperature and light are the main factors affecting the anthocyanins biosynthesis in grape fruits (Spayd et al., 2002; Castellarin et al., 2007a). The expression of the anthocyanin biosynthetic genes is induced by low temperature and repressed by high temperature in various plant species (Dela et al., 2003; Lo Piero et al., 2005; Ubi et al., 2006).

The anthocyanin biosynthesis pathway (Fig. 1) is complex with branches leading to the synthesis of many different metabolites (Boss et al., 1996). The coordinate induction of the expression of genes of the anthocyanin pathway in grapevine after veraison suggests that the pathway is tightly controlled by regulatory genes, as has been observed in other plant species (Deluc et al., 2008).
There is extensive literature indicating that temperature has a greater influence on anthocyanin biosynthesis than light (Mori et al., 2007 and references therein). Thus, it is reported that optimum temperature for anthocyanins synthesis in grapes occurs between 15 and $27^{\circ} \mathrm{C}$, and temperature above $30^{\circ} \mathrm{C}$ induces degradation of these compounds. That is increased during the light period because of the activation of the corresponding enzymes during the day (Haselgrove et al., 2000; Spayd et al., 2002; Downey et al., 2004). It is also known that cool temperatures at nights, during the maturation period, have a positive effect in the final polyphenols content in the berry skin (Mori et al., 2005).

Cultivation of grapes under restricted water supply has long been regarded as an agronomic tool for increasing polyphenol content in berries. Although the concentration of anthocyanins and other phenolics compound has consistently increased in response to water deficit, it is unclear whether this higher concentration is only due to inhibited berry growth, lowered water content and higher concentration of solutes, or water stress actively triggers by itself the biosynthesis of phenolics compound (Castellarin et al., 2007b and reference therein).

Vine training affects the foliage architecture and the plant shape, both of them greatly influence the plant - environment interaction. Plant responses to radiation, air temperature, and soil water content are modified by the training system, which has also an important impact on the phenolic compounds content of raisins (Boss and Davies, 2001; Conde et al., 2007; Smart et al., 1991).

In Uruguay, the environmental and culture conditions are such that vine management in Lyre training system produces higher yield than the vines managed in vertical shoot positioned (VSP) 


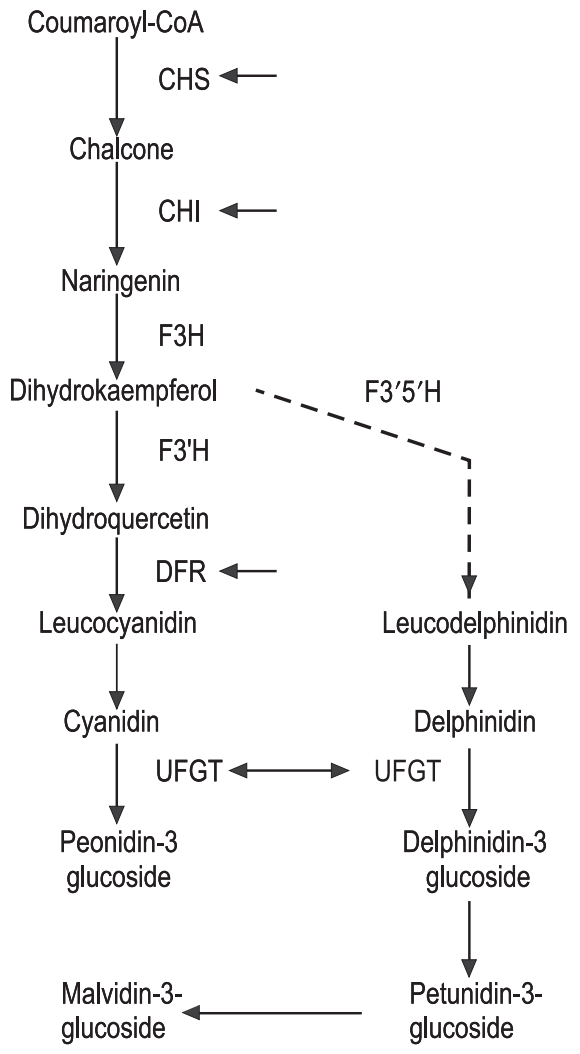

Fig. 1. A simplified diagram of anthocyanin biosynthesis pathway. Arrowheads indicate the gene coding for the enzymes analyzed in this study.

trellis system, without decrease in the enological quality of the berries (González-Neves, 2005). Berries of Tannat, the main black - red Vitis vinifera in Uruguay, have higher total anthocyanins content than Cabernet Sauvignon and Merlot (González-Neves et al., 2004, 2007).

In the present investigation, fruit anthocyanins accumulation in grapevine $(V$. vinifera $L) \mathrm{cv}$. Tannat and the expression of anthocyanins biosynthesis-related genes in a vineyard trained in Lyre and VSP system was studied.

\section{Material and methods}

Field plots and physiological measurements: Field experiments were conducted in commercial vineyards localized in the main viticulture region (Canelones; $34^{\circ} 35^{\prime} \mathrm{S}, 56^{\circ} 15^{\prime} \mathrm{W}$; Uruguay), with a climatic condition classified as $\mathrm{IS}_{\mathrm{A} 1} \mathrm{IH}_{\mathrm{A} 4} \mathrm{IF}_{\mathrm{A} 2}$ (climate moderated drougth, template warm. Vineyards of $V$. vinifera $\mathrm{cv}$. Tannat were trained in Lyre and VSP trellis systems, the agronomic information about the vineyards is shown in Table 1.

Leaf water potential (LWP) was monitored by pressure chamber technique (Scholander et al., 1965). Twenty adult, fresh and healthy leaves around the raisin (10 from east side, 10 from west side) were selected to perform the water potential measurements at flowering, veraison and harvest period. Measurements conducted at sunrise were scored as basal water potential.

Table 1. Characterstics of selected vineyards
Phenological stages scored from bud break were performed as proposed by Eichhorn and Lorenz (1977).

Grape samples: Samples of berries were taken from veraison until the harvest time, using the method described by Carbonneau et al. (1991), and sampling fractions of bunches in the middle zone of the spurs. Each fraction of the bunch had 3 to 5 berries randomly selected from the upper and lower parts of bunches, until 250 berries were collected. Samples were taken twice from each vineyard.

Fresh grape analysis: The harvest took place at the "technological maturity", according to the relationships between sugars, total acidity and $\mathrm{pH}$, that were analysed according to O.I.V. (2007).

Berries were weighed and crushed in a mortar in order to remove the skins, seeds and pulp. The skins and seeds were rinsed and separated from the pulp, dried afterwards with filter paper and weighed. Skins were frozen and kept at $-80^{\circ} \mathrm{C}$ until their analyses.

Grape extract analysis: In order to determine the total content of anthocyanins, macerations at $\mathrm{pH} 1$ were carried out according to the methodology proposed by Glories and Augustin (1993). The anthocyanins contents of the grape extracts were determined according to Ribéreau-Gayon and Stonestreet (1965), and were calculated according to González-Neves (2005). All measurements were performed twice.

Anthocyanins profiles: The frozen skins from the samples of grapes were macerated in a $12 \%(\mathrm{v} / \mathrm{v})$ ethanol $\mathrm{pH} 3.2$ solution. The volume of the solution was calculated according to González-Neves (2005), in a ratio 1:1 to the volume of the must. Macerations were carried out using the skins of 50 berries, with two replications per sample of grapes.

The anthocyanins contents of the extracts were determined by HPLC according to Revilla et al. (2001). The extracts were previously filtered with a $0.45 \mu \mathrm{m}$ membrane. A chromatographic system equipped with two pumps (Waters 510 and 515), a Rheodyne 7725i injector, a detector UV-VIS (Waters model 490E) with measurements at 313 and $530 \mathrm{~nm}$, and a C18 column (Phenomenex Luna) ( $150 \times 4.6 \mathrm{~mm})$ of $5 \mu \mathrm{m}$ (Waters Corp. USA) was used. Gradient conditions were carried out using two solvents. Solvent A: water-formic acid (90:10), solvent B: methanol-waterformic acid (45:45:10). Flow: $0.8 \mathrm{~mL} / \mathrm{min}$. Gradient: 35 to $95 \%$ of solvent B in $20 \mathrm{~min}, 95$ to $100 \%$ of solvent B in $5 \mathrm{~min}$, and isocratic with $100 \%$ of solvent B during 5 min.

Anthocyanins were identified taking into account the retention time of each peak and their relationship with the peak corresponding to malvidin-3-glucoside. The concentration of the 3-glucosides of delphinidin, cyanidin, malvidin, petunidin and peonidin were calculated considering a calibration curve with malvidin-3glucoside chloride (Extrasynthèse, France).

Gene expression analysis: A subsample of berries from the same sampling for anthocyanins analysis was used for extracting the

\begin{tabular}{cccccc}
\hline Age (years) & Rootstock & Distance $(\mathrm{m})$ & Density (plants ha $\left.{ }^{-1}\right)$ & Trellis system & Training \\
\hline 19 & $\mathrm{SO} 4$ & $3.20 \times 0.90$ & 3472 & Lyre & Cordon Royat \\
21 & $\mathrm{SO} 4$ & $2.30 \times 1.25$ & 3478 & VSP & Cordon Royat \\
\hline
\end{tabular}


RNA. Total RNA was extracted from berry skin following the procedure described by Chang et al. (1993). Ten $\mu \mathrm{g}$ of total RNA extracted from different sampling dates were resolved in agarose $(1.2 \% \mathrm{w} / \mathrm{v})$ under denaturing conditions and then transferred to a nylon membrane (Hybond $\mathrm{N}+$ ). Gene expression was analyzed by RNA blot analysis using ${ }^{32} \mathrm{P}$-ATP labeling (Amersham Pharmacia) of cDNA sequence from flavonoid 3-hydroxylase $(F 3 H)$, chalcone synthase (CHS), dihydroflavonol reductase (DFR), and UDP-glucoflavonoid 3-o-glucosyl transferase (UFGT) (Sparvoli et al., 1994).

Filters were exposed to X-ray film and the images were scanned in order to perform the image analysis (Image J 1.39 analysis software free access in http://rsb.info.ncb.gov/ij/). Relative expression was plotted using the comparison with the expression of a constitutive expressed gene (accession number BN000705; Bogs et al., 2005).

Statistical analyses: Differences between the treatments were tested for significance using the Statgraphics Plus package 4.1 (Statgraphics Corp., USA) and SAS/Stat Software Release 8.2 (S.A.S. Corp., USA). Means were separated by Tukey test.

\section{Results}

Anthocyanins accumulation and individual anthocyanidins profile in Lyre: When total anthocyanins content of grape extracts at $\mathrm{pH} 1$ were compared in two years analyzed, a difference at harvest date was observed (Fig. 2A). The evolution of the contents of the main individual anthocyanidins was quantified by HPLC in the extracts ( $\mathrm{pH}$ 3.2) from the skins (Fig. 2 B and C). The main anthocyanidins in the two years was the malvidin-3-glucoside, which reached at the same relative amount $28 \mathrm{DAV}$. The relative amount of malvidin in the year 1 was significantly higher than year 2 between 7 and 21 DAV (Fig. 2 B).

In general trisubstituted molecules (delphinidin, petunidin and malvidin) were predominant over the bisubstituted molecules (peonidin and cyanidin) (Fig. 2 C). In year 1 the relative content of malvidin increased during the ripening process, whereas the relative contents of the cyanidins and peonidins decreased in the same period (Fig. 2 B and C). During the year 2 a decrease of malvidin was detected from 21 to $35 \mathrm{DAV}$, and in the same period an increase of delphinidin was observed (Fig. 2 B and C).

Leaf water potential and anthocyanins-related gene expression: Values lower than $-1 \mathrm{MPa}$ in leaf water potential (LWP) were detected in the vineyards during verasion and near harvest periods in the year 1 and 2 respectively (Fig 3).

Analysis of gene expression was performed in order to analyze the relationship between the genes expression of anthocyanins pathway and the low leaf water potential. When levels of transcripts of the four genes studied were compared in two years, one of them with hydric deficit during veraison (year 1) and the other with hydric deficit during harvest (year 2), a great difference in the expression profiles was observed (Fig. 4).

The low LWP in year 1 during the veraison induced an earlier expression of all genes studied (Fig. 4). However, in year 2, low LWP during the last days of berries ripening process, near the harvest time, was related with a higher expression of $\mathrm{CHS}, \mathrm{F3H}$
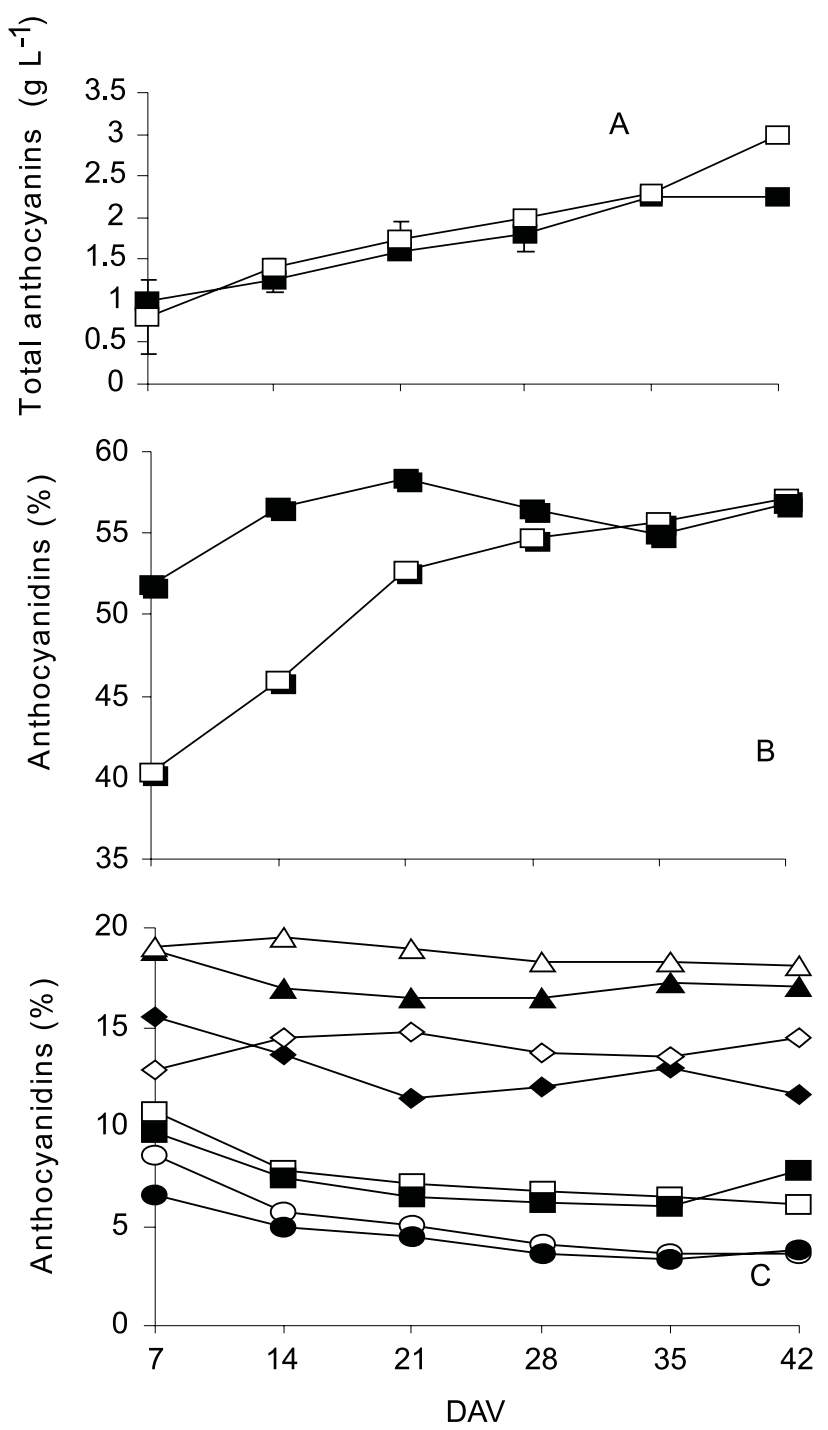

Fig. 2. Accumulation of total anthocyanins and relative amount of five anthocyanidins in berry of Lyre vines. White symbols year 1 and black symbol year 2. (A) total anthocyanins, (B) malvidin and (C) petunidin (triangles), delphinidin (diamonds), peonidin (squares) and cyanidins (circles). DAV indicates days after veraison. Vertical bars indicate SD.

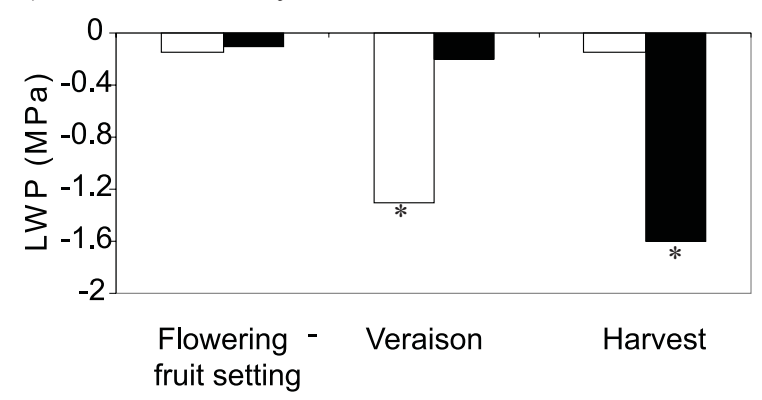

Fig. 3. Leaf water potential (LWP) in three stage of berry development (flowering-fruit setting, veraison and harvest) in Lyre managed vine. White bars year 1 and black bars year 2 . Asterisk indicates differential significance $P \leq 0.05$.

and DFR in the last sampling date compared with the same date of year 1 (Fig. 4).

In case of the UFGT, the expression pattern was the same in both years but a delay of 15 days was observed when no hydric deficit occurred during the veraison.

Anthocyanins accumulation and individual anthocyanidins profile in two trellis systems: In order to analyze the influence 
of plant architecture on anthocyanins profile, we compared the Lyre with vertical shoot positioned (VSP).
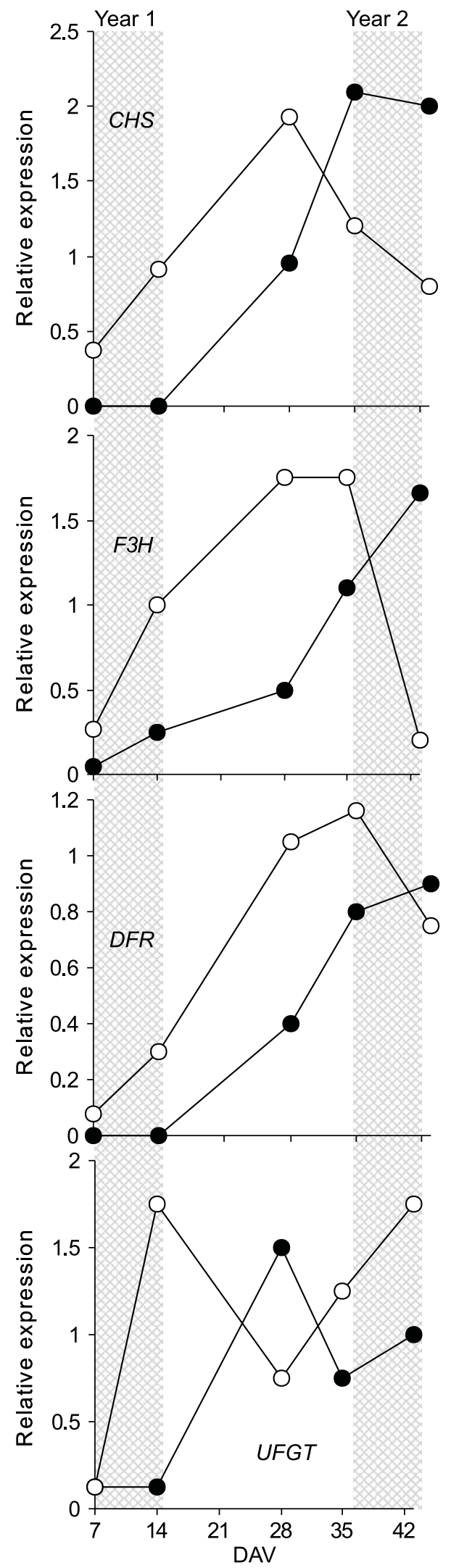

Fig. 4. Transcripts profiling of genes of the flavonoids pathways (CHS, $F 3 H, D F R$ and UFGT) in berry skins of Lyre managed vines. White circles year 1 and black circles year 2. DAV indicates days after veraison. Grey background indicate period of leaf water potential lower than $-1 \mathrm{MPa}$. Relative gene expression represents fold differences in gene expression relative to constitutive gene, for more details see materials and methods.
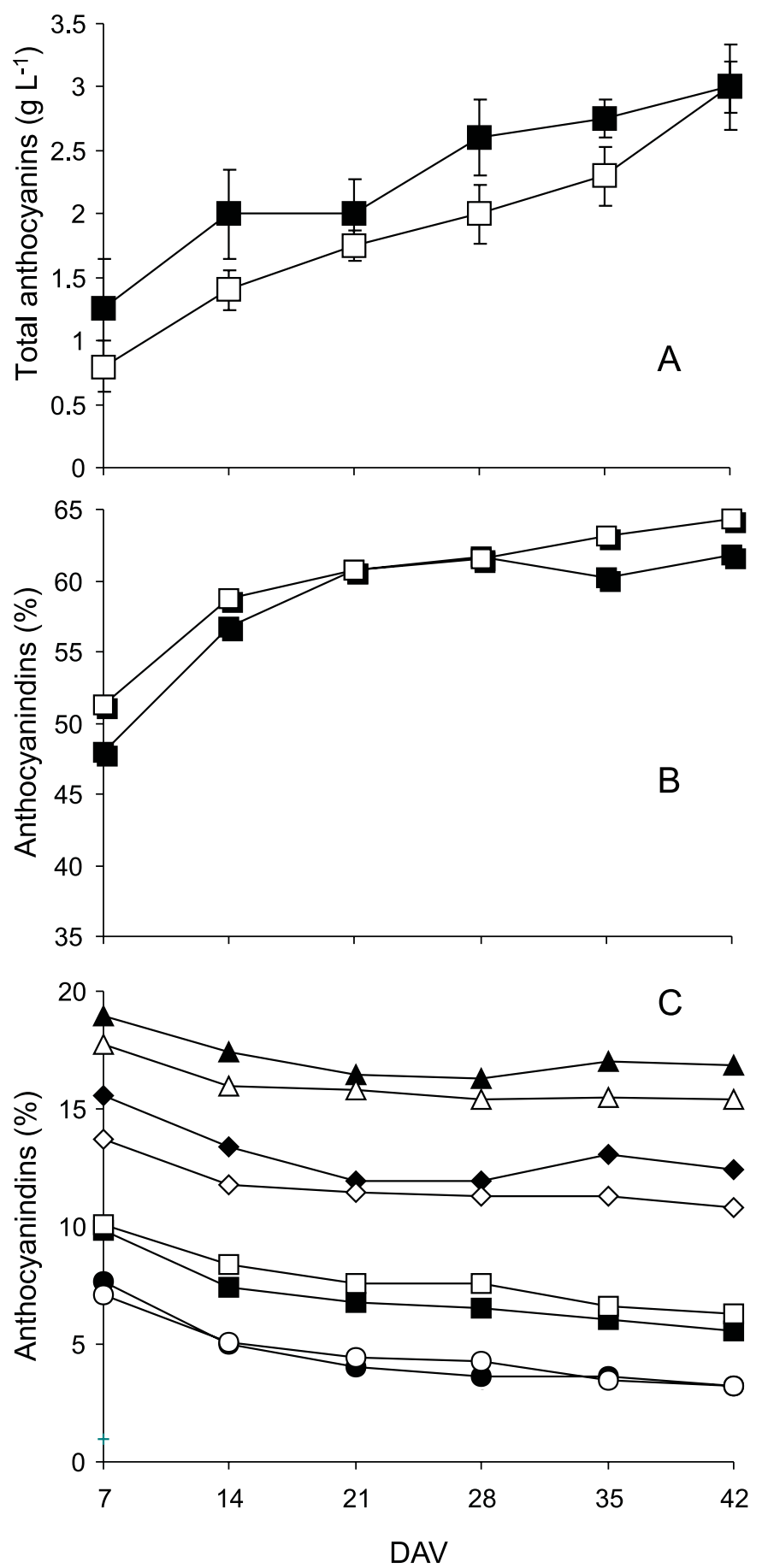

Fig. 5. Accumulation of total anthocyanins and relative amount of five anthocyanidins in berry skins of Lyre (white symbols) and vertical shoot positioned (VSP) (black symbols). (A) total anthocyanins, (B) malvidin and (C) petunidin (triangles), delphinidin (diamonds), peonidin (squares) and cyanidins (circles). DAV indicates days after veraison. Vertical bars indicate SD.

Berries of VSP system reached a higher concentration of anthocyanins at three of six sample dates compared with the values found in the grapes of Lyre system (Fig. 5 A). The berries of both training systems accumulated the same anthocyanins content at harvest, 42 days after veraison (DAV) (Fig. 5 A). When the changes of anthocyanins content between 14 and 21 DAV was analyzed for both training systems, no changes in the accumulation was observed in the VSP system in that period (Fig. $5 \mathrm{~A})$. The anthocyanidins profile showed a similar pattern between both training systems (Fig. $5 \mathrm{~B}$ and $\mathrm{C}$ ). The malvidin relative 

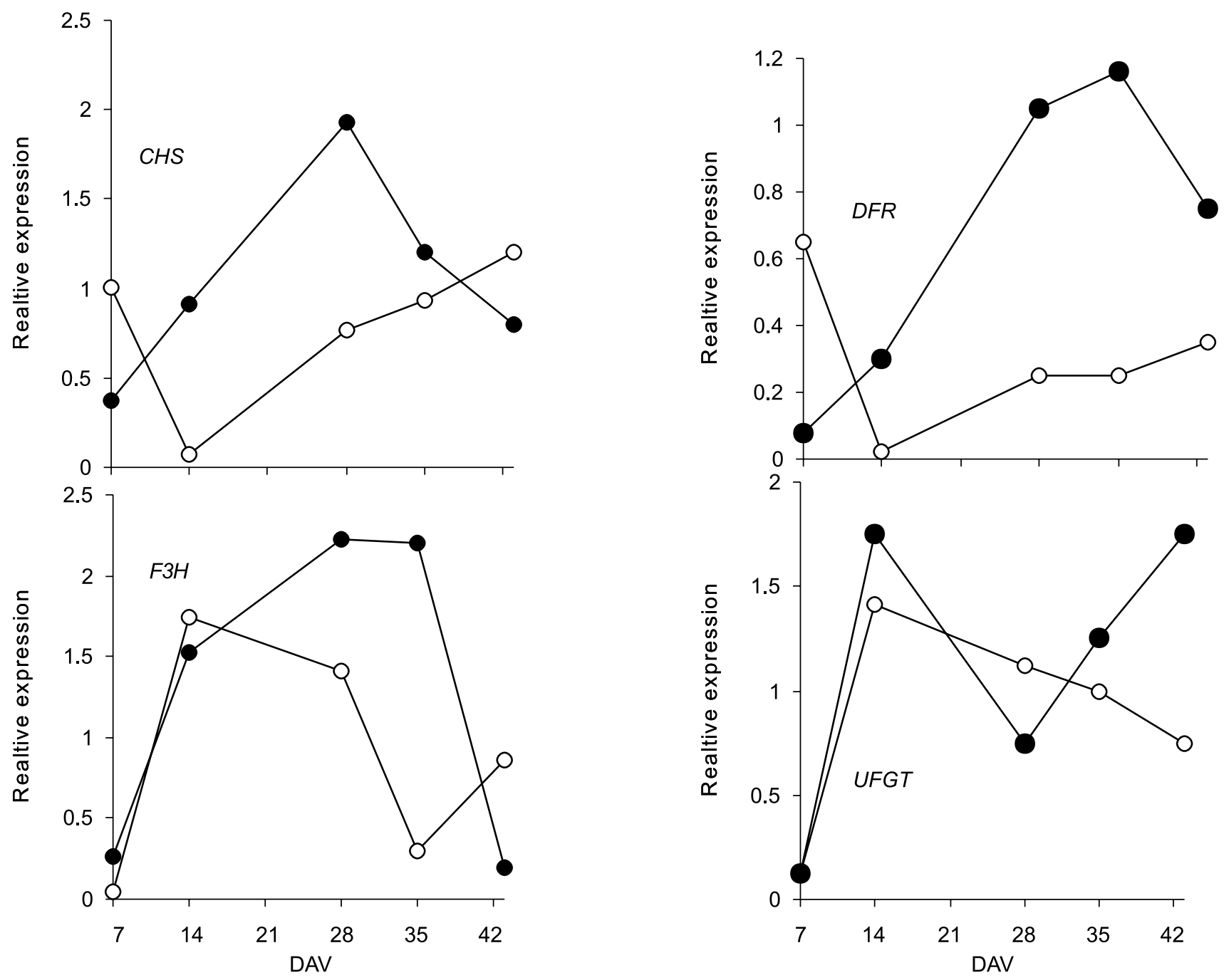

Fig. 6. Transcript profiling of genes of the flavonoids pathways (CHS, F3H, DFR and UFGT) in berry skin of Lyre (black circles) and vertical shoot positioned (VSP) (white circles) managed vines. DAV indicates days after veraison. Relative gene expression represents fold differences in gene expression relative to constitutive gene, for more details see Materials and methods.

content in 35 and 42 days was related negatively with petunidin and delphinidin relative contents in both training systems (Fig. $5 \mathrm{~B}$ and $\mathrm{C})$.

Training system and anthocyanins-related gene expression: In order to compare the possible incidence of training systems in the transcription of genes of the flavonoids pathways, the expression of four structural genes encoding for enzymes of the flavonoids pathway were analyzed from veraison to harvest. In general, increases in the expression of the four genes were detected in both training systems during the berry growth, and that was in agreement with the changes in the skin colour and the anthocyanins accumulation in the berries (Fig. 6). However, when the genes were analyzed individually, different gene expression profiles were found between both training systems.

CHS and DFR showed similar expression pattern in each training system. In Lyre, at 28 DAV and 35 DAV a maximum expression in CHS and DFR respectively was observed followed with a decrease in the two genes until harvest date (Fig. 6). In VSP a minimum in the expression of both genes was observed $14 \mathrm{DAV}$, which was reverted in next sampling dates. Between 14 and 35 DAV the expression levels for these genes were significantly lower in the VSP than in the Lyre system (Fig. 6).
F3H transcript profile was different in the two training systems analyzed. In VSP maximum expression was at 14 DAV and in Lyre maximum occurred at 28 DAV (Fig. 6).

The gene related with anthocyanins synthesis and storage, the UFGT gene, showed a strong induction at 14 DAV and similar time-course expression pattern in both training systems. However, differences in the transcripts accumulation at the last date of sampling was observed between Lyre and VSP trellis (Fig. 6).

\section{Discussion}

Viticulturists know that canopy management is essential to obtain a good quality of grape, and the trellis system is the main practice with influnence on this parameter. There are many factors that are influenced by the training systems, as quality and quantity of sunlight interception, canopy density, fruit temperature and water use efficiency (Smart and Robinson, 1991).

Higher yield under Lyre than other trellis systems, without loss of quality, has been observed for several years in cv. Tannat under the environmental conditions prevalent in the Uruguay viticulture region (González-Neves et al., 2004).

The interaction with the environmental factors like light exposure, 
the water use availability, and temperature defines the ultimate composition of anthocyanins of the fruit. Many environmental factors affect the gene expression in the berry however the water deficit during the berry ripening process is one the most important factor. There are three stages of the vine growth and development when drought could considerably affect the berry size and composition; these are at flowering, at veraison and at harvest time (Keller et al., 2005; Ojeda, 2005; Roby et al., 2004).

Our study showed that total anthocyanins of berries of Tannat vines managed in Lyre were similar in both years of the study during the ripening process, but the content was different at harvest (Fig. 2 A). In the year 2 a hydric deficit around harvest time (Fig. 3) could explain the higher anthocyanins content in this year than to year 1 (Fig. 2 A).

It has been reported that water deficit stimulates hydroxylation and methoxylation of the flavonoid B-ring, accelerates particularly tri-substitued anthocyanins biosynthesis, and also promotes the conversion of hydroxylated anthocyanins into their methoxylated derivatives (Castellarin et al., 2007b). The same study indicated similar consequences as results of early and late water deficits, in transient expression pattern that favours trisubstitued anthocyanins accumulation. However, the malvidin proportions found in Tannat reflects more the early hydric deficit noted in the vines in the year 1 , whereas petunidin and delphinidin proportions were increased in the grapes obtained in year 2 when the hydric deficit occurred near the harvest (Fig. 2 B).

Taking in account the data obtained under hydric deficit period (veraison or harvest) we could propose that a period of water deficit close to veraison induce prematurely the expression of the genes involved in the anthocyanins pathways with the results of accumulation of these compounds in the berries (Fig. 2 and 4). Similar results were obtained when a field experimental trail was carried out with two dates of water stress. In that study an early water deficit accelerated sugar accumulation and the onset of anthocyanin synthesis after veraison (Casterllarin et al., 2007a).

On the other hand, when hydric deficit period was close to harvest, a higher gene expression in the last stage of berry development was found with the exception of UFGT (Fig. 4). Our results indicate the gene expression profile is affected by the hydric deficit period, what could explain the increased accumulation of anthocyanins in the first weeks after verasion and at harvest date. The water deficit occurring in two different berry growth periods (veraison and harvest) modified the expression profile of the studied genes in Lyre training system. Water deficit at veraison induces an earlier and higher expression of CHS, F3H, DFR, and UFGT genes than in years with a water deficit at harvest.

In Uruguay, periods of high temperature during the summer are common, then the temperature must be considered when studying berry metabolism. On the other hand, it has been reported that anthocyanins accumulation is inhibited in the skins of black - red grapes in hot regions (Haselgrove et al., 2000; Spayd et al., 2002; Downey et al., 2004). We think that possibly a high temperature period (above $35^{\circ} \mathrm{C}$ ) $14 \mathrm{DAV}$ (data not shown) could be the cause of the different behavior between VSP and Lyres vines in anthocyanins accumulation.

Lyre training system could have higher capacity to maintain the thermal homeostasis of the raisin, which is reflected in a lower variation of the slope for the anthocyanins accumulation during ripening (Fig. 5).

A recent study has shown that $C H S, D F R$ and UFGT expression are negatively affected by high temperatures and provided definitive evidence of anthocyanins loss in the skin of grape berries due to high temperature (Mori et al., 2007).

Individual analysis of the transcription of four genes in Lyre training and VSP trellis systems evidences a higher expression at 14 DAV of CHS, DFR and UFGT in Lyre (Fig. 6). Canopy architecture in VSP could be responsible of the higher raisin temperatures and inhibit of the anthocyanins pathway gene transcription mentioned above (Fig. 6). However, this explanation could not be applied to the $\mathrm{F} 3 \mathrm{H}$ gene expression, since it showed similar level to Lyre (Fig. 6). A change in the gene expression pattern in different training systems is evidenced by the analysis of expression of flavonoid pathway CHR, F3H, DFR and UFGT (Fig. 6).

Previous studies that monitored the temperature inside and outside of the Merlot showed lower values in Lyre compared with VSP trellis system (Ferrer, 2007), which related with the major anthocyanin accumulation found in the berries of Lyre (González-Neves, 2005).

Apart from the effect of temperature and light on anthocyanin accumulation, recent research also shows some shift in anthocyanin composition with temperature. The results indicate that in warm-climate the fruits would tend to have a higher proportion of malvidin, petunidin and delphinidin coumaroyl derivatives, while in cool-climate and shaded fruits would have more non-acylated glucosides and acetyl-glucosides of peonidin and cyanidin (Spayd et al., 2002). Our results showed that in both year and in both training systems the individual anthocyanidins profile in berries of $\mathrm{cv}$. Tannat was similar to those found in vines cultivated in warm-climate.

A future work related with raisin microclimate training systemdependence and gene expression will be useful to improve the understanding of environmental signals which determine the polyphenols content in the grapes.

\section{Acknowledgments}

The authors thank Establecimiento Juanicó, Viñas Varela-Zarranz for kindly providing the vineyards for the study. This study was funded by FCE_8054. Authors want to dedicate this manuscript to Ing. Agr. Julio Omar Borsani Estevez (1934-2006) and Dr. Maria Fernanda Agius Guadalupe (1972-2005) for their invaluable collaboration and permanent encouragement for maintaining the excellence of the work.

\section{References}

Bogs, J., M.O. Downey, J.S. Harvey, A.R. Ashton, G.J. Tanner and S.P. Robinson, 2005. Proanthocyanidin synthesis and expression of genes encoding leucoanthocyanidin reductase and anthocyanidin reductase in developing grape berries and grapevine leaves. Plant Physiol., 139: 652-663.

Boss P.K. and C. Davies, 2001. Molecular biology of sugar and anthocyanin accumulation in grape berries. In: Molecular Biology and Biotechnology of the Grapevine. (eds.). K.A. RoubelakisAngelakis, Kluwer Academic Publishers, Dordrecht, The Netherlands. pp 1-33. 
Boss, P., C. Davies and S. Robinson, 1996. Analysis of the expression of anthocyanin pathway genes in developing Vitis vinifera L. cv. Shiraz grape berries and the implication for pathway regulation. Plant Physiol., 111: 1059-1066.

Carbonneau, A., A.Moueix, N. Leclair and J. Renoux, 1991. Proposition d'une méthode de prélèvement de raisins à partir de l'analyse de l'hétérogéneité de maturation sur un cep. Bull. de l'OIV 727/728 679-690

Castellarin, S., M. Matthews, G. Di Gaspero and G. Gambeta, 2007a. Water deficit accelerate ripening and induce changes in gene expression regulating flavonoid biosynthesis in grape berries. Planta, 227: 101-112.

Castellarin, S., A. Pfeiffer, P. Sivilotti, M. Degan, E. Peterlunger and G. Di Gaspero, 2007b. Transcriptional regulation of anthocyanin biosynthesis in ripening fruits of grapevine under seasonal water deficit. Plant Cell Environ., 30: 1381-1399.

Chang, S., J. Puryear and J. Canrey, 1993. A simple method for isolating RNA from pine tree. Plant Mol. Biol. Rep., 11: 113-116.

Conde, C., P. Silva, N .Fontes, A. Díaz, R. Tavarez, M. Sousa, A. Agasse, S. Delrrot and H. Gerós, 2007. Biochemical change throughout grape berry development and fruit and wine quality. Food, 1: 1-22.

Dela, G., E. Or, R. Ovadia, A. Nissin - Levi, D. Weiss and M. OrenShamir, 2003. Changes in anthocyanin concentration and composition in Jaguar rose flowers due to transient high temperature conditions. Plant Sci.,164: 333-340.

Deluc, L., J. Bogs, A.R. Walker, T. Ferrier, A. Decendit, J.M. Merillon, S.P. Robinson and F. Barrieu, 2008. The transcription factor $V V M Y B 5 b$ contributes to the regulation of anthocyanin and proanthocyanidin biosynthesis in developing grape berries. Plant Physiol., 147: 2041-2053.

Downey, M.O., J.S. Harvey and S.P. Robinson, 2004. The effect of bunch shading on berries development and flavonoid accumulation in Shiraz grapes. Austral. J. Grape Wine Res., 10: 55-73.

Eichorn, K.W. and D.H. Lorenz, 1977. Phänologishche enwicklungsstadien der rebe. Nachrichtenbl.Dtsch. Pflanzenschutzdienstes (Braunschweig), 29: $119-120$.

Ferrer, M. 2007. Etude du climat des régions viticoles de l’Uruguay, des variations climatiques et de l'interaction apportée par le microclimat et l'écophysiologie des systèmes de conduite Espalier et Lyre sur Merlot. Ph.D. Diss., Ecole Nationale Supérieure Agronomique - Université de Montpellier II -France 2007. 360pp.

Glories, Y. and M. Augustin, 1993. Maturité phénolique du raisin, conséquences technologiques: application aux millésimes 1991 et 1992. C.R. Colloque Journée Techn. CIVB, Bordeaux pp. 56-61.

González-Neves, G., D. Charamelo, J. Balado, L. Barreiro, R. Bochicchio, G. Gatto, G. Gil, A. Tessore, A. Carbonneau and M. Moutounet, 2004. Phenolic potential of Tannat, Cabernet-Sauvignon and Merlot grapes and their correspondence with wine composition. Anal. Chim. Acta, 513: 191-196.

González Neves, G., 2005. Etude de la composition polyphénolique des raisins et de vins des cépages Merlot, Cabernet sauvignon et Tannat provenant de vignes conduites en lyre et en espalier dans le sud de l'Uruguay. Ph.D. Diss. ENSA Montpellier, 2005. 279pp.

González-Neves, G., J. Franco, L. Barreiro, G. Gil, M. Moutounet and A. Carbonneau, 2007. Varietal differentiation of Tannat, Cabernet sauvignon and Merlot grapes and wines according to their anthocyanic composition. Eur. Food Res. Tech., 225: 111-117.
Haselgrove, L., D. Botting, R.Van Heeswijck, P. B. Hoj, P. R. Dry, C. Ford and P. Iland, 2000. Canopy microclimate and berry composition: the effect of bunch exposure on the phenolic composition of Vitis vinifera L cv. Shiraz grape berries. Aust. J. Grape Wine Res., 6: 141-149.

Keller, M., L.J. Mills, R.L. Wample and S.E. Spayd, 2004. Crop load management in "Concord" grapes using different pruning techniques. Amer. J. Enol. and Vitcult., 55: 35-49.

Keller, M., L.J. Mills, R.L. Wample and S.E. Spayd, 2005. Cluster thinning effects on three deficit- irrigated Vitis vinifera cultivars. Amer. J. Enol. Viticult., 56: 91-103.

Lo Piero, A.R., I. Puglisi, P. Rapisarda and G. Petrone, 2005. Anthocyanins accumulation and related gene expression in red orange fruit induced by low temperature storage. J. Agr. Food Chem., 53: 9083-9088.

Mori, K., N. Goto-Yamamotom, M. Kitayama and K. Hasizume, 2007. Loss of anthocyanins in red-wine grape under high temperature. $J$. Exp. Bot., 58: 1935-1945.

Mori, K., H. Saito, N. Goto-Yamamoto, M. Kitayama, S. Kobayashi, S. Sugaya, H. Gemma and K. Hashizume, 2005. Effects of abscisic acid treatment and night temperatures on anthocyanin composition in Pinot noir grapes. Vitis, 44: 161-165.

O.I.V., 2007. Récueil des méthodes internationales d'analyse des vins et des moûts. Office International de la Vigne et du Vin. Paris, France.

Ojeda, H., N. Carrillo, L. Deis, B. Tisseyre, M. Heywang and A. Carbonneau, 2005. Precision viticulture and water status II: quantitative and qualitative performance of different within field zones, defined from water potential mapping. C.R. XIV GESCO, 2: 741-748.

Revilla E., E. García-Beneytez, F. Cabello, G. Marti-Ortega and J.M. Ryan, 2001. Value of high-performance liquid chromatographic analysis of anthocyanins in the differentiation of red grape cultivars and red wines made from them. J. Chroma., 915: 53-60.

Ribereau-Gayon, P. and E. Stonestreet, 1965. Le dosage des anthocyanes dans le vins rouges. Bull. Soc. Chim., 9: 26-49.

Roby, G., J.F. Harbertson, D.A. Adams and M.A. Matthews, 2004. Berry size and vine water deficits as factors in winegrape composition: anthocyanins and tannins. Aust. J. Grape Wine Res., 10: 100-107.

Scholander, P.F., H.T. Hammel, E.D. Bradstreet and E.A. Hemmingsen, 1965. Sap pressure in vascular plants. Science, 148: 339-346.

Smart, R.E. and M.D. Robinson, 1991. Sunlight into Wine: A Handbook for Winegrape Canopy Management. Winetitles, Adelaida, Australia.

Sparvoli, F., C. Martin, A. Scienza, G. Gavazzi and C. Tonelli, 1994. Cloning and molecular analysis of structural genes involved in flavonoid and stilbene biosynttheis in grape (Vitis vinifera L.). Plant Mol. Biol., 24: 743-755.

Spayd, S.E., J.M. Tarara, D.L. Mee and J. C. Ferguson, 2002. Separation of sunlight and temperature effects on the composition of Vitis vinifera cv. Merlot berries. Amer. J. Enol. Viticult., 53: 171-182.

Ubi. V.W., C. Honda, H. Bessho, S. Kondo, M. Wada, S. Kobayashi and T. Moriguchi, 2006. Expression analysis of anthocyanin biosynthetic genes in apple skin: effect of UV-B and temperature. Plant Sci., 170: $571-578$.

Winkel-Shirley, B. 2002. Biosynthesis of flavonoids and effects of stress. Curr. Opin. Plant Biol., 5: 218-23. 